\title{
Funding gap for locust crisis
}

\author{
East Africa is experiencing the worst desert locust outbreak in decades. Climate events have facilitated breeding \\ of the swarming pest across the region, and with a surge in the locust population expected in coming weeks urgent
} action is needed to avert a humanitarian crisis.

T wenty million people in six of the eight East African countries most affected by an ongoing desert locust outbreak - Ethiopia, Kenya, Somalia, South Sudan, Uganda and the United Republic of Tanzania - are at risk of acute food insecurity ${ }^{1}$. The situation is not under control (Somalia declared a national emergency in February) and the FAO's Director-General Qu Dongyu has called for rapid action to avert a humanitarian crisis.

Considered among the most destructive of migratory pests, an adult locust can consume $2 \mathrm{~g}$ of vegetation per day, affecting crops, pasture and fodder. A swarm typically holds 20 to 150 million locusts per square kilometre and can migrate hundreds of kilometres per day, invading areas covering millions of square kilometres ${ }^{2,3}$. An active swarm, therefore, can decimate crops and pastures within a very short period of time. In the current outbreak, swarms $60-\mathrm{km}$ long and $40-\mathrm{km}$ wide have been reported in Kenya ${ }^{1}$. Devastating effects on crops and livelihoods have already been felt, but with the main cropping season approaching much worse is expected. Conditions have facilitated successful breeding of the pest and in the coming weeks the FAO predicts a 400 -fold upsurge in the population of swarming, gregarious locusts in the region.

Centuries of art and literature have depicted the plague of locusts, often drawn down or vanquished by biblical figures. However, the present outbreak has, in part, a pressing anthropogenic aetiology - climate change - and the responsibility for its control is international.

That global warming could increase the risk of desert locust infestations was proposed over ten years ago ${ }^{4}$, and in February, the UN Secretary-General António Guterres stated that the current outbreak is linked to the effects of climate change: "warmer seas mean more cyclones generating the perfect breeding ground for locusts". The outbreak has its origins in 2018, when an unprecedented series of cyclones in the Arabian Peninsula enabled the warm and wet conditions the desert locust requires to breed

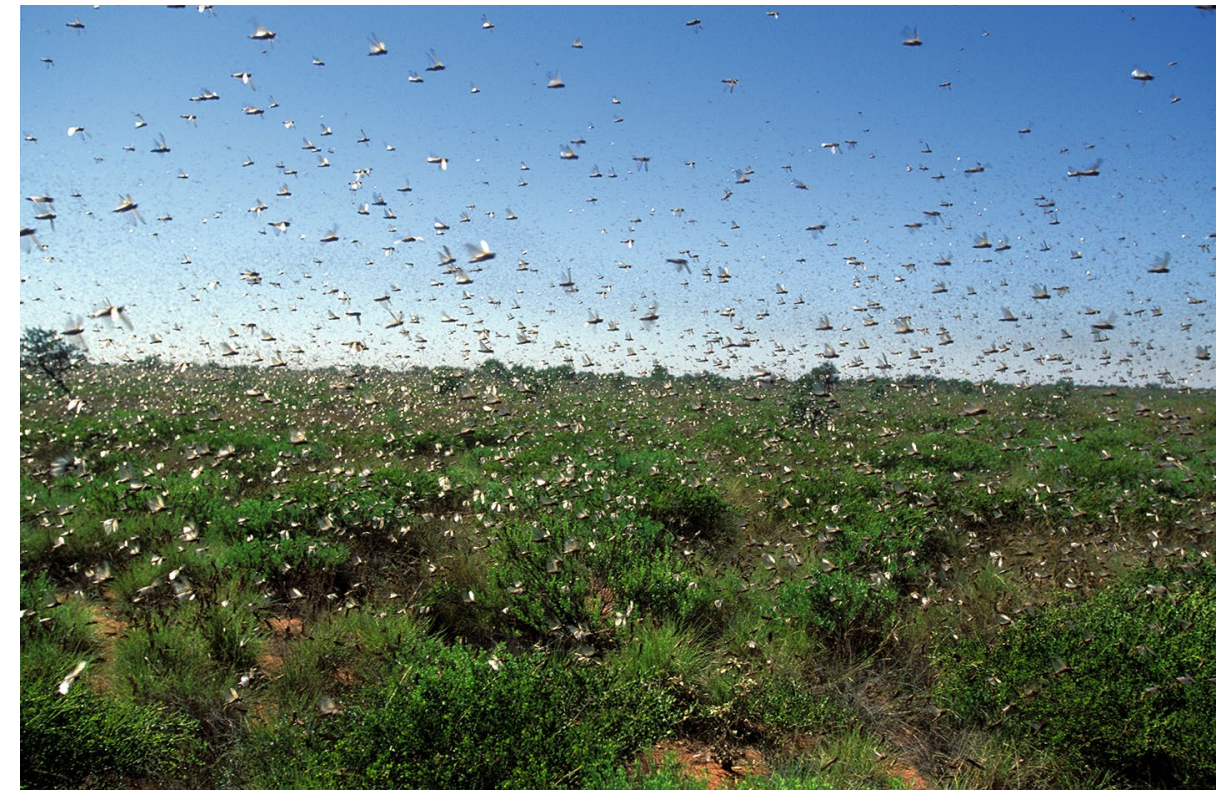

Credit: John Carnemolla/Corbis Documentary/Getty

and band undetected in remote regions. Weather systems related to the Indian Ocean Dipole facilitated their migration. Though our focus here is migration west, devastating outbreaks of the desert locust have been experienced to the east with Pakistan declaring an emergency in February.

The FAO has put an immediate price tag of US $\$ 138$ million for rapid response and anticipatory action - curbing the spread of the desert locust and safeguarding livelihoods - to the crisis in the Greater Horn of Africa. They say the maths is clear: about half the funding is needed for surveillance, ground and aerial control, and coordination efforts; the other half is needed for livelihoods and food security of farmers and herders and they have called on the international community to act now through funding. By the end of February, however, just US\$69 million had been pledged by donors 5 .

The resilience of farmers in East Africa to climate shocks is tested time and time again, and the risk of severe acute food insecurity is ever-present. As coronavirus seizes the headlines, there is a real danger that the international community becomes immune to this most alarming crisis that has developed, and is worsening in East Africa, and that the funds needed to control the situation become more difficult to secure.

Published online: 17 March 2020

https://doi.org/10.1038/s43016-020-0058-1

References

1. Desert Locust Crisis: Appeal for Rapid Response and Anticipatory Action in the Greater Horn of Africa (FAO, 2020); https:// go.nature.com/2TG0RZT

2. Desert Locust Guidelines (FAO, 2001); https://go.nature. com/2VYzziW

3. Zhang, L., Lecoq, M., Latchininsky, A. \& Hunter, D. Annu. Rev. Entomol. 64, 15-34 (2019).

4. Yu, G., Shen, H. \& Liu, J. J. Geophys. Res. Atmos. 114 D18104 (2009).

5. FAO welcomes $€ 17$ million contribution from Germany to combat the impact of the Desert Locust upsurge in East Africa. FAO (28 February 2020); https://go.nature.com/336UnGq 